\title{
The effect of intravenous low dose ketamine for reducing postoperative sore throat
}

\author{
Sun Young Park ${ }^{1}$, Sang Hyun Kim ${ }^{2}$, Jung Il Noh ${ }^{1}$, Su Myoung Lee ${ }^{1}$, Mun Gyu Kim ${ }^{1}$, Sang Ho Kim , \\ Si Young $\mathrm{Ok}^{1}$, and Soon Im Kim ${ }^{1}$ \\ Department of Anesthesiology and Pain Medicine, Soonchunhyang University Hospital, College of Medicine, Soonchunhyang \\ University, ${ }^{1}$ Seoul, ${ }^{2}$ Bucheon, Korea
}

Background: This study was performed to evaluate the effectiveness of intravenous low dose ketamine for reducing the incidence and severity of postoperative sore throat (POST).

Methods: This was a prospective, randomized, double-blind clinical trial. The study population consisted of 70 patients between 20 and 70 years old who were classified as American Society of Anesthesiologists I-II and were scheduled for elective laparoscopic cholecystectomy. The patients were divided randomly into two groups. Patients in the ketamine group received an intravenous injection of $0.5 \mathrm{mg} / \mathrm{kg}$ of ketamine just before induction, followed by $10 \mu \mathrm{g} / \mathrm{kg} / \mathrm{min}$ throughout the operation. Patients in the control group received intravenous saline instead of ketamine. The patients were interviewed 1,6 , and $24 \mathrm{~h}$ after the operation. The incidence and severity of POST were recorded.

Results: No significant differences in the incidence and severity of POST during the $24 \mathrm{~h}$ after the operation were found between the two groups (21/31 in the ketamine group vs. 26/34 in the control group, $\mathrm{P}=0.398$ ).

Conclusions: Intravenous injection of low dose ketamine was not effective for reducing POST. (Korean J Anesthesiol 2010; 59: 22-26)

Key Words: Complications, Intubation, Ketamine.

Received: March 24, 2010. Revised: 1st, March 29, 2010; 2nd, April 6, 2010. Accepted: April 20, 2010.

Corresponding author: Sun Young Park, M.D., Department of Anesthesiology and Pain Medicine, Soonchunhyang University Hospital, College of Medicine, Soonchunhyang University, 657, Hannam-dong, Yongsan-gu, Seoul 420-767, Korea. Tel: 82-2-709-9302, Fax: 82-2-790-0394, E-mail: sunnypark97@gmail.com

(c) This is an open-access article distributed under the terms of the Creative Commons Attribution Non-Commercial License (http:// creativecommons.org/licenses/by-nc/3.0/), which permits unrestricted non-commercial use, distribution, and reproduction in any medium, provided the original work is properly cited. 


\section{Introduction}

Protection of sensory neurons against central sensitization may offer relief from pain occurring after injury or surgery [1]. Based on this theory, preemptive analgesia has been advocated as an effective tool to manage postoperative pain $[2,3]$. The mechanisms involved in preemptive analgesia may include intercepting nociceptive input, increasing the threshold for nociception, and blocking N-methyl-D-aspartate (NMDA) receptor activation. Therefore, NMDA receptor antagonists may improve preemptive analgesia. Ketamine is the most potent of all NMDA antagonists currently available for use in humans [4]. It binds noncompetitively to the NMDA receptors and inhibits the NMDA receptor-mediated central sensitization, potentially reducing postoperative pain $[5,6]$. Although the role of ketamine in the treatment of postoperative pain remains controversial $[7,8]$, optimal regimens of ketamine should manage acute pain while minimizing the adverse effects. Recent trials have demonstrated that, when added as an adjunct to general anesthesia, intravenous sub-anesthetic low dose ketamine reduces postoperative pain and opioid requirements without adverse effects [9-13].

Many patients complain of postoperative sore throat (POST) after tracheal intubation. Although POST is not a major complication and is self-limiting, it causes a great deal of patient dissatisfaction. Therefore, it would be useful if the intravenous ketamine as an analgesic adjunct to general anesthesia could also reduce POST. In this study, we evaluated the effect of intravenous low dose ketamine on POST.

\section{Materials and Methods}

This was a prospective, randomized, double-blind clinical trial, and it was approved by the institutional review board (SCHBC_IRB_08). After obtaining written informed consent, patients scheduled for an elective laparoscopic cholecystectomy

Table 1. Patient Characteristics

\begin{tabular}{lccc}
\hline \multicolumn{1}{c}{ Groups } & $\begin{array}{c}\text { Ketamine group } \\
(\mathrm{n}=31)\end{array}$ & $\begin{array}{c}\text { Control group } \\
(\mathrm{n}=34)\end{array}$ & $\mathrm{P}$ \\
\hline Age (yr) & $41.5 \pm 10.3$ & $40.4 \pm 9.9$ & 0.644 \\
Gender (M/F) & $9 / 22$ & $9 / 25$ & 0.912 \\
Weight (kg) & $63.4 \pm 14.0$ & $63.1 \pm 11.9$ & 0.914 \\
ASA (I/II) & $26 / 5$ & $30 / 4$ & 0.541 \\
Smoking history (yes/no) & $13 / 18$ & $12 / 22$ & 0.618 \\
Duration of tracheal & $100.6 \pm 38.3$ & $109.2 \pm 38.6$ & 0.870 \\
intubation (min) & & & \\
Cough (n) & 4 & 4 & 0.891 \\
Hoarseness (n) & 18 & 21 & 0.766 \\
\hline
\end{tabular}

Data are given as the mean \pm SD or absolute numbers. ASA: American Society of Anesthesiologists. were enrolled between April and July, 2008. Patients were between 20 and 70 years of age and had American Society of Anesthesiologists (ASA) physical status I-II. Both groups were similar with respect to age, gender, weight, ASA status, smoking history, and duration of tracheal intubation (Table 1).

Exclusion criteria included a history of recent respiratory tract infection or sore throat and preoperative use of analgesics such as non-steroidal anti-inflammatory drugs or opioids. Patients who required more than one attempt for tracheal intubation, had a nasogastric tube, or had a duration of tracheal intubation of $<60$ min or $>300$ min were eliminated from the analysis.

All patients were premedicated with an intramuscular injection of $0.2 \mathrm{mg}$ glycopyrrolate $30 \mathrm{~min}$ before their arrival in the operating room. Monitoring in the operating room consisted of three-lead electrocardiography, noninvasive arterial blood pressure, pulse oximetry, and end-tidal $\mathrm{CO}_{2}$. Before surgery, the patients were divided randomly into two groups using a computer-generated random number table and the sealed envelope method. Patients in the ketamine group were injected with $0.5 \mathrm{mg} / \mathrm{kg}$ ketamine $(5 \mathrm{mg} / \mathrm{ml}$ ) just before induction, followed by an infusion of $10 \mu \mathrm{g} / \mathrm{kg} / \mathrm{min}$ throughout the operation. Patients in the control group received the same volume of saline. The study drug was prepared in a syringe labeled with the patient number, but without a drug name, by one nurse who knew the group allocation. All anesthetic procedures were performed by experienced anesthesiologists who were blinded to the group allocation. The investigators who collected data and interviewed patients did not perform any of the procedures, and they were blinded to the group allocation. All patients were blinded to the group allocation.

Induction was accomplished with $100 \mu \mathrm{g}$ fentanyl and propofol ( $2 \mathrm{mg} / \mathrm{kg})$, followed by rocuronium $(0.6 \mathrm{mg} / \mathrm{kg})$. A direct laryngoscopy with a Macintosh \#3 blade and tracheal intubation were performed $2 \mathrm{~min}$ after the rocuronium injection. The trachea was intubated with a high volume/low pressure cuff endotracheal tube (Euromedical; Kedah, Malaysia) with an internal diameter of 8.0 or $7.0 \mathrm{~mm}$ for male or female patients, respectively. Immediately after intubation, the tracheal tube cuff was inflated with room air until no air leakage could be heard at a peak airway pressure of $20 \mathrm{cmH}_{2} \mathrm{O}$. Then, the cuff pressure was adjusted to $10-20 \mathrm{cmH}_{2} \mathrm{O}$ using a handheld pressure gauge (Portex Cuff Inflator/Pressure Gauge, SIMS Portex, Hythe, Kent, UK). No humidifier or heat and moisture exchangers were used in either group. Anesthesia was maintained with $50 \% \mathrm{O}_{2}$ in air, 7-8 vol\% desflurane, and rocuronium. The end-tidal $\mathrm{CO}_{2}$ was maintained at 35-40 $\mathrm{mmHg}$.

At the end of surgery, the patients were given $10 \mathrm{mg}$ pyridostigmine and $0.2 \mathrm{mg}$ glycopyrrolate intravenously, and the lungs were ventilated with $100 \% \mathrm{O}_{2}$ until the patient was fully awake and had recovered from the muscle relaxation. After 
gently aspirating the oral secretions, the cuff was deflated fully, and the tracheal tube was removed. Ketamine infusion was discontinued after extubation, and the duration of the tracheal intubation was recorded.

A single dose of intravenous ketorolac $30 \mathrm{mg}$ was given to all the patients in the postanesthesia care unit, and additional fentanyl was administered according to the degree of postoperative complaints about wound pains. No other analgesics were used. The total dose of fentanyl administered during induction and within 24 hours after the operation was recorded.

The incidences of POST, cough, and hoarseness were measured using direct questions at 1, 6, and 24 hours after the operation. The visual analog scale (VAS) scores of POST and wound pain were also recorded at the same times.

Statistical analyses were performed using SPSS (ver. 14.0, SPSS Inc., Chicago, IL, USA). The unpaired t-test was used for comparisons between groups in age, weight, duration of tracheal intubation, VAS scores of POST and wound pain, and the total dose of fentanyl administered during induction and 24 hours after the operation. Between-group differences in gender, ASA status, smoking history, and the incidence of POST, cough, and hoarseness 24 hours after the operation were analyzed using the chi-square and Fisher's exact tests, as appropriate. The results are expressed as the mean $\pm \mathrm{SD}$ or absolute number. $\mathrm{P}<$ 0.05 was considered significant.

Table 2. The Incidence of POST, Cough, and Hoarseness

\begin{tabular}{lccc}
\hline \multicolumn{1}{c}{ Groups } & $\begin{array}{c}\text { Ketamine group } \\
(\mathrm{n}=31)\end{array}$ & $\begin{array}{c}\text { Control group } \\
(\mathrm{n}=34)\end{array}$ & $\mathrm{P}$ \\
\hline POST (n) & 21 & 26 & 0.398 \\
Cough (n) & 4 & 4 & 0.891 \\
Hoarseness (n) & 18 & 21 & 0.766 \\
\hline
\end{tabular}

Data are given as the absolute numbers. No significant differences are found between the groups. POST: postoperative sore throat.

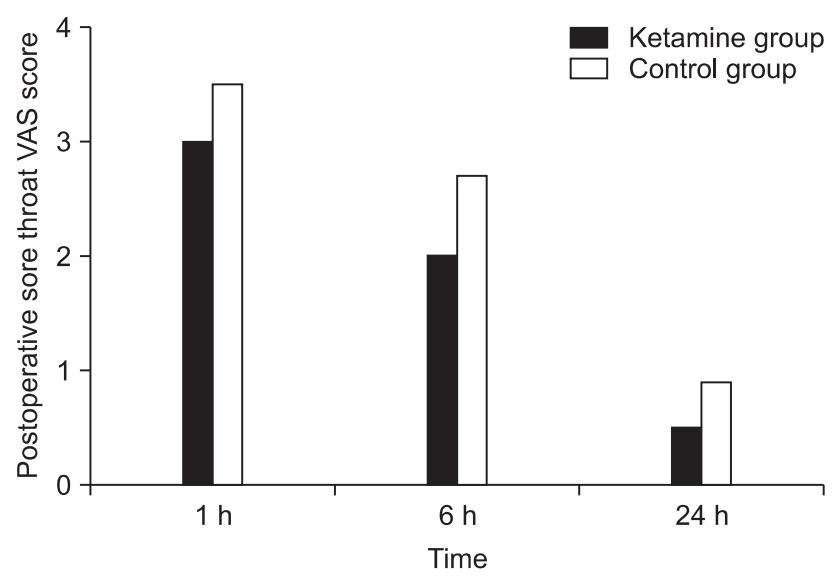

Fig. 1. The visual analog scale (VAS) scores of postoperative sore throat. No significant differences are found between the groups.
The primary outcome variable was the incidence of POST during the 24 hours after the operation. According to a previous study, we presumed the incidence of POST to be 65\% [14]. The sample size was estimated from the assumption that a $50 \%$ reduction in the incidence of POST would be clinically relevant. Power analysis suggested that a minimum of 31 patients in each group would be needed for $\beta=0.20$ and $\alpha=0.05$. To compensate for potential dropouts, 70 patients were enrolled.

\section{Results}

Of the 70 patients enrolled, two patients required more than one attempt for intubation, and the duration of intubation was $<60 \mathrm{~min}$ in one patient and $>300 \mathrm{~min}$ in two patients, so they were excluded from the analysis. Of the remaining 65 patients, 31 were in the ketamine group and 34 in the control group.

During the 24 hours after the operation, no significant difference in the incidence of POST or the incidence of cough and hoarseness was observed between the two groups (Table 2). The VAS scores of POST and wound pain were not significantly different between the two groups (Fig. 1, 2). The total doses of fentanyl administered during induction and for 24 hours after the operation were $32.3 \pm 47.4 \mu \mathrm{g}$ in the ketamine group and $40.3 \pm 43.6 \mu \mathrm{g}$ in the control group $(\mathrm{P}=0.483)$.

\section{Discussion}

We infused low dose ketamine intravenously throughout the period of endotracheal intubation under the hypothesis that preemptive ketamine would reduce POST. However, intravenous low dose ketamine had no effect on the incidence and severity of POST.

Ketamine is in the middle of the affinity range of uncompetitive NMDA antagonists. Preemptive administration of ketamine

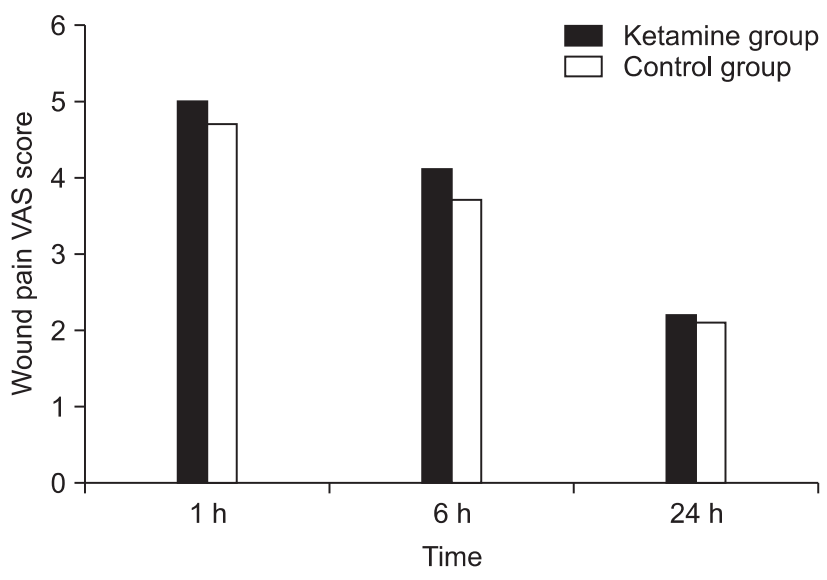

Fig. 2. The visual analog scale (VAS) scores of wound pain. No significant differences are found between the groups. 
before and during surgery could block the development of central sensitization in the postoperative period and thus maximize their analgesic efficacy [1]. A number of controlled studies have demonstrated the benefit of this approach $[10,11,15]$. In the study of Menigaux et al. [9], intravenous injection of small dose ketamine after the induction of anesthesia improved postoperative analgesia. Kwok et al. [10] concluded that small preoperative dose of ketamine produced preemptive analgesia. Argiriadou et al. [13] presented that preincisional and repeated intraoperative small-dose $\mathrm{S}(+)$ ketamine improves postoperative pain relief. We expected that the preemptive effect of ketamine could also reduce POST.

Nociceptive and inflammatory signals are generated throughout surgery and after the procedure. Therefore, a single administration of a short-acting drug such as ketamine either before or after a procedure will not provide analgesia that lasts far into the postoperative period. To prevent pathologic pain, ketamine needs to be applied at least throughout the operation [16], and onset can be delayed if a loading dose is not administered [17]. Therefore, we infused ketamine continuously throughout the period of endotracheal intubation, with a preinduction bolus.

When ketamine is administered systemically, it may cause adverse cardiovascular or respiratory effects and sedation, dreams, hallucinations, and other psychomimetic adverse reactions. Therefore, we used low-dose ketamine, which does not cause respiratory depression [7] and only minimal changes in heart rate and blood pressure [17]. A sub-anesthetic dose of ketamine did not increase the incidence of postoperative adverse psychic effects, sedation, or nausea and vomiting $[9,10,18]$. Schmid et al. [13] defined low dose ketamine as a bolus dose less than $1 \mathrm{mg} / \mathrm{kg}$ and continuous administration at a rate of $\leq 20 \mu \mathrm{g} / \mathrm{kg} / \mathrm{min}$.

In a long-term outcome trial on adenocarcinoma surgery with general or epidural anesthesia, ketamine injected as a $0.5 \mathrm{mg} /$ $\mathrm{kg}$ pre-incisional bolus followed by an intraoperative infusion of $250 \mu \mathrm{g} / \mathrm{kg} / \mathrm{h}$ reduced postoperative morphine needs and the incidence of residual pain [9]. Kararmaz et al. [12] demonstrated that intravenous ketamine had an improved analgesic or opioid-sparing effect when it was combined with epidural bupivacaine and morphine after an intraoperative ketamine infusion of $500 \mu \mathrm{g} / \mathrm{kg} / \mathrm{h}$ preceded by a pre-incisional $0.5 \mathrm{mg} /$ $\mathrm{kg}$ bolus. Fu et al. [19] reported preemptive ketamine decreases postoperative opioid requirement when given $0.5 \mathrm{mg} / \mathrm{kg}$ before surgical incision followed by an infusion of $10 \mu \mathrm{g} / \mathrm{kg} / \mathrm{min}$. Based on these results, we injected ketamine as a $0.5 \mathrm{mg} / \mathrm{kg}$ preinduction bolus followed by a $10 \mu \mathrm{g} / \mathrm{kg} / \mathrm{min}$ intraoperative infusion. This dosing schedule is similar to or greater than that used in previous studies and the recommended dose for painful procedures by Himmelseher et al. [16] (0.5 mg/kg preincisional bolus followed by an intraoperative infusion of $500 \mu \mathrm{g} / \mathrm{kg} /$ hr). We expected that this dose of ketamine might affect POST, but it did not. We did not observe an effect on POST and did not detect a difference in postoperative pain VAS or the doses of fentanyl administered. Therefore, it may be an insufficient dose or a third dose range in which ketamine has no analgesic potency on its own $[17,20,21]$; this is a possible explanation for our negative result.

Canbay et al. [14] found that a ketamine gargle (40 mg ketamine in saline $30 \mathrm{ml}$; gargled for $30 \mathrm{~s} 5 \mathrm{~min}$ before induction) reduced the incidence and severity of POST in patients undergoing septorhinoplasty under general anesthesia with endotracheal intubation, potentially because of local anti-inflammatory and anti-hyperalgesic effect of ketamine. However, because Canbay et al. did not measure plasma ketamine levels, they could not rule out a systemic effect of ketamine. Our results suggest that topical application, and not systemic ketamine, may influence POST, reduce local inflammation, and mediate the peripheral anti-nociceptive effect.

The incidence of POST in our study was higher than expected. Women tend to have a higher incidence of postoperative sore throat than men $[22,23]$, and our study population included more women then men, which might cause the high incidence of POST. The interview method could also affect the results, as direct questioning can increase the perceived incidence of sore throat $[22,24]$.

In conclusion, low dose ketamine did not affect POST as a $0.5 \mathrm{mg} / \mathrm{kg}$ preinduction bolus followed by an intraoperative infusion of $10 \mu \mathrm{g} / \mathrm{kg} / \mathrm{min}$. However, we did not compare the effects of various dose regimens. Therefore, we cannot reach a firm conclusion about the effect of low-dose ketamine on POST.

\section{References}

1. Wall PD. The prevention of postoperative pain. Pain 1988; 33: 28990.

2. Katz J, Kavanagh BP, Sandler AN, Nierenberg H, Boylan JF, Friedlander M, et al. Preemptive analgesia. clinical evidence of neuroplasticity contributing to postoperative pain. Anesthesiology 1992; 77: 439-46.

3. Woolf CJ, Chong MS. Preemptive analgesia--treating postoperative pain by preventing the establishment of central sensitization. Anesth Analg 1993; 77: 362-79.

4. Chizh BA. Low dose ketamine: a therapeutic and research tool to explore N-methyl-D-aspartate (NMDA) receptor-mediated plasticity in pain pathways. J Psychopharmacol 2007; 21: 259-71.

5. Oye I, Paulsen O, Maurset A. Effects of ketamine on sensory perception: evidence for a role of N-methyl-D-aspartate receptors. J Pharmacol Exp Ther 1992; 260: 1209-13.

6. Orser BA, Pennefather PS, MacDonald JF. Multiple mechanisms of ketamine blockade of $\mathrm{N}$-methyl-D-spartate receptors. Anesthesiology 1997; 86: 903-17. 
7. Edwards ND, Fletcher A, Cole JR, Peacock JE. Combined infusions of morphine and ketamine for postoperative pain in elderly patients. Anaesthesia 1993; 48: 124-7.

8. Jaksch W, Lang S, Reichhalter R, Raab G, Dann K, Fitzal S. Perioperative small-dose $\mathrm{S}(+)$-ketamine has no incremental beneficial effects on postoperative pain when standard-practice opioid infusions are used. Anesth Analg 2002; 94: 981-6.

9. Menigaux C, Guignard B, Fletcher D, Sessler DI, Dupont X, Chauvin M. Intraoperative small-dose ketamine enhances analgesia after outpatient knee arthroscopy. Anesth Analg 2001; 93: 606-12.

10. Kwok RF, Lim J, Chan MT, Gin T, Chiu WK. Preoperative ketamine improves postoperative analgesia after gynecologic laparoscopic surgery. Anesth Analg 2004; 98: 1044-9.

11. De Kock M, Lavand'homme P, Waterloos H. 'Balanced analgesia' in the perioperative period: is there a place for ketamine? Pain 2001; 92: 373-80.

12. Kararmaz A, Kaya S, Karaman H, Turhanoglu S, Ozyilmaz MA. Intraoperative intravenous ketamine in combination with epidural analgesia: postoperative analgesia after renal surgery. Anesth Analg 2003; 97: 1092-6.

13. Argiriadou H, Himmelseher S, Papagiannopoulou P, Georgiou M, Kanakoudis F, Giala M, et al. Improvement of pain treatment after major abdominal surgery by intravenous S+-ketamine. Anesth Analg 2004; 98: 1413-8.

14. Canbay O, Celebi N, Sahin A, Celiker V, Ozgen S, Aypar U. Ketamine gargle for attenuating postoperative sore throat. Br J Anaesth 2008; 100: 490-3.
15. Aida S, Yamakura T, Baba H, Taga K, Fukuda S, Shimoji K. Preemptive analgesia by intravenous low-dose ketamine and epidural morphine in gastrectomy: a randomized double-blind study. Anesthesiology 2000; 92: 1624-30.

16. Himmelseher S, Durieux ME. Ketamine for perioperative pain management. Anesthesiology 2005; 102: 211-20.

17. Schmid RL, Sandler AN, Katz J. Use and efficacy of low-dose ketamine in the management of acute postoperative pain: a review of current techniques and outcomes. Pain 1999; 82: 111-25.

18. Dahl V, Ernoe PE, Steen T, Raeder JC, White PF. Does ketamine have preemptive effects in women undergoing abdominal hysterectomy procedures? Anesth Analg 2000; 90: 1419-22.

19. Fu ES, Miguel R, Scharf JE. Preemptive ketamine decreases postoperative narcotic requirements in patients undergoing abdominal surgery. Anesth Analg 1997; 84: 1086-90.

20. Chapman V, Dickenson AH. The combination of NMDA antagonism and morphine produces profound antinociception in the rat dorsal horn. Brain Res 1992; 573: 321-3.

21. Dickenson AH. Combination therapy in analgesia; seeking synergy. Curr Opin Anaesthesiol 1993; 6: 861-5.

22. Kim WJ, Oh HK. A Clinical study of sore throat after endotracheal intubation. Korean J Anestheisol 1977; 10: 41-5.

23. Maruyama K, Sakai H, Miyazawa H, Toda N, linuma Y, Mochizuki N, et al. Sore throat and hoarseness after total intravenous anaesthesia. Br J Anaesth 2004; 92: 541-3.

24. Harding CJ, McVey FK. Interview method affects incidence of postoperative sore throat. Anaesthesia 1987; 42: 1104-7. 